\title{
A NEW ANGLE ON RUSSELL'S "INEXTRICABLE TANGLE" OVER MEANING AND DENOTATION
}

\author{
Francisco A. Rodriguez-Consuegra
}

Lógica, Historia y Filosofía de la Ciencia / Universidad de Barcelona 08028 Barcelona, Spain

\section{INTRODUCTION}

$\mathrm{T}$

he following is a brief study of one of Russell's unpublished manuscripts from 1905 ("On Fundamentals", mIgos). It is very interesting because it contributes to providing the precise background to "On Denoring", chiefly on two points: (i) the rather cryptic passages where Russell succeeds in dispensing with the distinction between meaning and denotation (which is reduced to an "inextricable tangle"); (ii) the precise formulation of the main definition of the theory of descriptions in itself, which did not appear symbolically in any published version until "Mathematical Logic as Based on the Theory of Types" (Russell rgo8) and Principia.

As for the first point, the difficult passages from "On Denoting" are contained in pages 48- 50 , as constituting the third of a series of three puzzles, all of which are supposed to receive the corresponding solution through the new theory of descriptions. Russell begins by introducing a distinction between the meaning and the denotation of a denoting phrase in connection with the notion of a denoting complex (e.g., "the centre of the solar system"), then he notices a great difficulty in trying to construct a coherent theory this way. By using $C$ for the denotation and " $C$ " for the meaning of some denoting phrase, the difficulty is described by writing that "we cannot succeed in both preserving the connexion of meaning and denotation and preventing them from being one and the same", for when we put the denoting complex into a proposition, the proposition seems to be about $C$, the 
denotation, while if "the meaning of $C$ " is the subject of the proposition, then the true subject seems to be the meaning of the denotation. However, this leads us to say that it is the meaning that is a complex and has denotation; so there is no longer a complex having both meaning and denotation (pp. 49-50). Therefore, in speaking of $C$ itself as a subject, the true subject is rather something which denotes $C$, and in speaking of " $C$ " as the meaning, what we really refer to must be rather something which denotes the meaning. That is when Russell arrives at the "inextricable tangle" passage, which I think is worth quoting:

Thus it would seem that " $C$ " and $C$ are different entities, such that " $C$ " denotes $C$; but this cannot be an explanation, because the relation of " $C$ " to $C$ remains wholly mysterious; and where are we to find the denoting complex " $C$ " which is to denote $C$ ?'Moreover, when Coccurs in a proposition, it is not only the denotation that occurs ...; yet, on the view in question, $C$ is only the denotation, the meaning being wholly relegated to " $C$ ". This is an inextricable tangle, and seems to prove that the whole distinction of meaning and denotation has been wrongly conceived. (LK, p. 5o)

I think "On Fundamentals" offers us some clarification of the involved puzzle, which to my knowledge constitutes its first occurrence. The difficulties in the published version proceed mainly from Russell's habit of inserting fragments from old manuscripts directly into new manuscripts without providing enough background. I do not assert that in the unpublished version everything is clear; far from that. But I think that by combining the study of "On Denoting" with that of "On Fundamentals" things become somewhat clearer. That is why I am convinced the relevant passages are worth publishing.

I have no room in this note to make comments on the literature, but I want to point out the need to study all the relevant materials written by Russell on this particular argument before proposing a particular interpretation. Coffa (in his 1980 , an "ingenious" dialogue between the Russell of The Principles of Mathematics, the Fregean one and that from 1905) pointed out the relevance of mI905, but after that he does not quote either its content or that of previous related manuscripts, ${ }^{\mathrm{I}}$ and terms "heroic efforts" the attempts by Hochberg ( 1976

${ }^{\text {I }}$ I have studied the rest of the manuscripts relevant for the theory of descriptions and 1978 ), Ayer (1977) and Blackburn and Code (1978) to throw some light on the celebrated passages from "On Denoting" only by saying: "Regrettably, no coherent sense can be made of those three pages, or the several passages in ( ${ }^{\prime} 056$ ) [my migos] from which they derive." We shall see that some of the passages of "On Fundamentals" may be of some help in improving our understanding of "On Denoting".

As for the second point, Russell's first formulation of the main definition of the theory of descriptions, thanks to this manuscript we are now able to examine the first appearance of the method to constructively define (i.e. to eliminate) the definite article. Contrary to a rather general belief, the key idea did not appear symbolically in "On Denoting", which is again the extremity of the iceberg constituted by the manuscripts of that period, but in "On Fundamentals". These passages should be of interest to scholars working on Russell's theory of descriptions and help the general reader to see the origins of Russell's theory in a new and truer historical light, being a good example of his general way of working in those years.

Given the extent of the manuscript, I shall limit my brief account to describe Russell's progress beyond what was achieved in the earlier manuscripts and point out the relevant ideas for a better understanding of "On Denoting". The extant material is divided into two parts: the first one (fos. I-I7) is constituted by a set of discussions about the problem of meaning and denotation; the second one (fos. 18-81) contains a set of paragraphs whose extension is increasing ( $\$ \$ 1-97$ ), and whose purpose is to state the "facts" relevant to the logical foundation of mathematics.

\section{MEANING AND DENOTATION IN A DENOTING COMPLEX}

The more important trait of the first part of the manuscript is that it starts from the objectivity of the meaning, in the Fregean line of for-

and the evolution of the general problem of denotation from Principles to I905 in my and the
I99o.
2 Cof

${ }^{2}$ Coffa $x 980$, p. 69 n.8. Unfortunately he does not mention writings so relevant (although again they do not use the unpublished manuscripts) as: Butler 1954, Searle I958, Welding I97I and, mainly, Cassin 1970 (which, however, suffers especially because of the lack of a study of the unpublished material). 
mer manuscripts. But after that, and probably as an effect of the problems caused by the mutual self-application of meaning and denotation (see below), it continues to consider the possibility of eliminating meaning as an "entity". With that, it would be necessary neither to oppose meaning and denotation to one another, nor to really maintain the separation in itself, leaving only the denoting complex and the entity denoted by it. Because of that Russell continually works with the difference between meaning-positions and entity-positions of denoting complexes (among which we find descriptions) inside wider complexes (e.g. propositions).

The discussion starts from the following "Important Principle: If a denoting expression denotes a meaning, and is put in a meaningposition in a complex, it will be the meaning meant by the denoting expression, not the meaning denoted, that will occur there" (mIgos, fol. 3). And this principle seems to state the meaning (Frege's Sinn) as something objective, for it can be denoted. Immediately Russell says that with this principle we can see why "things go wrong": when we link a variable in a meaning-position and a variable in an entityposition, we must avoid denoting complexes: in the first case they stand for their meaning; in the second for their denotation. Whereas when we try to vary what appears as meaning in a denoting complex, "we must be able to specify what varies, and this can only be done if what varies occurs as entity, not as meaning" (fol. 4). That is to say: "a denoting meaning can only be spoken of by means of denoting concepts which denote the meaning in question" (fol. 7), and for that when we make "the substitution of what is denoted for a denoting concept, it is essential that what is denoted should not itself denote" (fol. 9). On the contrary we would interpret it (erroneously) as meaning.

The beginning of a solution appears with the rejection of the objectivity of the meaning implicitly caused by the presentation of denotation as being: "Every complex has meaning and being. Qua meaning, it is not one entity, but a compound of several" (fol. I2). So, although we continue to maintain the distinction between meaning and denotation, and denoting complexes have both (which is essential for the solution of the identity paradoxes), meaning is now something linguistic and symbolic (as indication was in the Principles). Thus denotation results in being identified with the entity itself, losing its character of a twofold relation because of the failure of one of the two objects (the meaning, which is no longer objective): "What the complex is is what we have called its denotation. There is no entity which is the complex as meaning, because the complex as meaning is not an entity" ( $i b i d$ ); also: "the meaning per se is not one entity, and can't be denoted" (fol. I4).

This line gives the basis for a definite solution to the problem of denoting complexes (whose notation is $\left(C(x)^{3}\right)$, transforming them into a matter of "structure" (fol. I4). Now they can be regarded as functions, which, as Frege claimed, are not entities. So, in $(C l x)$ " $C$ is inseparable, and is nothing by itself; for it is part of the meaning of $(C \times x)$, and is therefore not necessarily one entity at all" (fol. I2). Hence the later pre-eminence of Frege's context principle, which is implicit in the theory of descriptions. ${ }^{4}$

\section{THE FIRST "INEXTRICABLE TANGLE"}

The second part of "On Fundamentals" embraces the context of "On Denoting" and starts from the mentioned solution: a complex occurs as meaning when it is affirmed, whereas it occurs as being when its truth is affirmed (fol. I8, $\$ \$_{3}-4$ ), which respectively determine meaning-positions and entity-positions (see above). Immediately Russell considers the way in which complexes occur in other complexes: "When a complex $A$ occurs in a complex $B$, if $A$ occurs as meaning, its constituents are constituents of $B$, but if it occurs as entity, its constituents are not constituents of $B^{\prime \prime}(\$ 19)$. This has the

3 Probably taken from Cayley (according to a personal communication by I. Grattan-Guinness), and already in Whitehead's Universal Algebra (Cambridge: 1898), p. I44 (which was pointed out to me by Nick Griffin).

4 Russell is somewhat doubtful before so drastic a decision: "... we must admit that a complex as entity, at least when it is propositional, depends upon its constituents, and becomes a different entity if we substitute for a denoting constituent either another with the same denotation, or the denotation itself. Thus when $(C l x)$ is propositional, if not in all cases, the $x$ must be a constituent of $(C \emptyset x)$ as entity, not only of $(C \vee x)$ as meaning. Thus the theory begun on $\mathrm{p}$. $\mathrm{I} 2$ must be wrong. We must not say that the being of a denoting complex is its denotation, nor must we deny that there is such an entity as the meaning of a complex" (mIgos, fol. 17). But finally the view obtained the pre-eminence through the recognition of the objectivity of the complex in itself, and the rejection of its meaning as entity. 
consequence that, for example, "the author of Waverley" occurs in "Scott is the author of Waverley" in four senses. As entity: (I) when it may be replaced by any other entity without loss of significance; (2) when its denotation may be substituted without altering the truthvalue of the proposition. As meaning: (3) when its constituents are constituents of the proposition; (4) when 'the proposition, tho' it retains its truth-value, does not retain its identity, when we substitute for 'the author of Waverley' either 'Scott' or a complex which denotes
Scott" $\left(\$_{2 I}\right)$.

This leads Russell to speak of primary and secondary occurrences $(\$ \$ 23-30)$, and their mutual relations, which has the consequence (among others) of returning to the ontological distinction of the Prin ciples between concepts and things, the former being those entities which can occur only as meanings and the latter those which are not concepts $\left(\$_{30}\right)$.

At this point we arrive at the climax: the moment when the paradox destroying the meaning-denotation distinction appears. It coincides with the moment (the more important one) in the later "On Denoting" when the solution mentioned above is presented: when referring to denoting complexes $\left(\$_{35}\right)$ :

When a concept has meaning and denotation, if we wish to say anything about the meaning, we must put it in an entity-position; but if we put it itself in an entity-position, we shall be really speaking about the denotation, not the meaning, for that is always the case when a denoting complex is put in any entity-position. Thus in order to speak about the meaning, we must substitute for the meaning something which denotes the meaning. Hence the plexes which denote complexes can only be approached by means of comcommas are. If wete those meanings. This is what complexes in inverted commas are. If we say "'any man' is a denoting complex", "any man" stands for "the meaning of the complex 'any man", which is a denoting concept. But this is circular; for we use "any man" in explaining "any man". And the circle is unavoidable. For if we say "the meaning of any man", that will stand for the meaning of the denotation of any man, which is not what we want.

At last Russell realizes that the key to the problem is the mutual application of the two notions. If we insist in maintaining them, Russell adds, we shall be forced to admit that, $C$ being a denoting complex: (I) the meaning of $C^{\prime}$ does not denote the meaning of $C$, but the meaning of the denotation of $C$ "; and (2) "the denotation of $C$ ' does not mean the denotation of $C$, but 'the denotation of $C^{\prime \prime}$ " $(\$ 37)$. For Russell such facts show that meaning and denotation are inseparable, and

the impossibility of inventing a symbolism which will avoid the necessity of distinguishing the two sides in complexes. For "the meaning of $C$ " and "the denotation of $C$ " both have the two sides, and are therefore in no way less two-fold than " $C$ " itself. (Ibid.)

The conclusion is already unavoidable: when we speak of a complex it consists in " $C$ ", but nor in $C$, therefore we have no longer "one complex with the two aspects of meaning and denotation, but two entities, ' $C$ ', the complex, and $C$, the denotation of ' $C$ '" $(\$ 39)$. Thus we come back to the view of the Principles by only reducing the meaning to language and the denotation to reality.

Thus, the main point against the distinction between meaning and denotation is that any attempt to speak about the meaning or the denotation of a denoting phrase leads us to other phrases which, if the theory is correct, also need to have meaning and denotation, which is finally circular. Therefore, the difficult arguments from "On Denoting" become somewhat simplified, as soon as one realizes that the type of vicious circle Russell had in mind was of the form of an endless regress, which is not made very clear in "On Denoting".

Russell returned to a similar argument to the one we have seen in the manuscript, but it took place six years later, in "Knowledge by Acquaintance and Knowledge by Description" (rgIx). There we read that if in "Scott is the author of Waverley" we regard the denotation of "the author of Waverley" as the denotation of what "the author of Waverley" means, we cannot avoid the endless regress:

Let us call the meaning of "the author of Waverley" $M$. Thus $M$ is what "the author of Waverley" means. Then we are to suppose that "Scott is the author of Waverley" means "Scott is the denotation of $M$ ". But here we are explaining our proposition by another of the same form, and thus we have made no progress towards a real explanation. "The denotation of $M$ ", like "the author of Waverley"; has both meaning and denotation, on the theory we are examining. If we call its meaning $M^{\prime}$, our proposition becomes "Scott is the denotation of $M^{\prime \prime}$. But this leads at once to an endless regress. (IgII, pp. 216-17) 
Curiously enough, the endless regress involved in the three occurrences of the argument appears when we try to eliminate a "form" by resorting to a proposition which has the same form, and this seems to me to be somewhat equivalent to Bradley's paradox against relations: if we say that relations are entities relating terms, then we have to give an account of how they are related to those terms, which immediately leads us to an endless regress. Thus, the ghost of the old master survived Russell's official abandonment of some of his explicit doctrines
in his "idealistic" period.

\section{THE FIRST THEORY OF DESCRIPTIONS}

The last step consists in applying this to descriptions. Russell's method here is already the same as the one followed in the published version, with the sole difference that instead of taking a function of an individual as the object of the definition $((2 x)(\phi x))$, the thing defined here is this same function, but with regard to the unique member of a unit class; in symbols: $\left(\phi^{\prime} \mathfrak{r}^{\prime} u\right)$. First Russell states the definition in terms of any denoting descriptive complex (fol. $38, \$_{40}$ ):

$$
\phi^{\prime} C .=:(\exists y): C \text { denotes } y: C \text { denotes } z \cdot \supset_{z} \cdot z=y: \phi^{x} y,
$$

then he applies it to descriptions in particular (ibid.): 5

$$
\phi^{\prime} \mathfrak{x}^{\prime} u_{\bullet}=:(\exists y): y \in u: z \in u \cdot \supset_{z} \cdot z=y: \phi^{\prime} y
$$

Consequences are derived accurately. First of all, we can define now all propositions about $\imath^{\prime} u$, "which is all we need". Therefore: "On this view, 'the author of Waverley' has no significance at all by itself,

5 The canonical symbolical expression of "Mathematical Logic as Based on the Theory of Types" (rgo8) and Principia:

$$
\psi\{(\mathfrak{x})(\phi x)\} . \equiv .(\exists b): \phi x . \equiv_{x} \cdot x=b: \psi b .
$$

appeared first in a letter to Jourdain of 13 January 1906 (in Grattan-Guinness $1977, p$ 70 ), although there is a previous occurrence of this definition in the manuscript "On
Substitution", written in December am indebted to Gregory Landini for this last remark.) but propositions in which it occurs have significance" (fol. $38, \$ 40$ ), which involves the pre-eminence of the Fregean (and Peanian) ${ }^{6}$ principle of the context over the Moorean one of the "constituents" (through the idea of defining "in use"). Secondly, the problem of denotation vanishes, together with the Fregean need for a conventional denotation: " "Thus in regard to denoting phrases of this sort, the question of meaning and denotation ceases to exist" (ibid., fol. 38, $\$ 40)$. Finally, it seems that this conclusion can be generalized to all complexes:

The above theory leads to the result that all denoting functions are meaningless in themselves, and are only significant when they occur as constituents of propositions. Hence all complexes become undenoting: they will be such as propositions, propositional functions, modes of combination, etc. (Fol. 39, \$4I)

We can imagine the way from this to the substitutional theory, the theory of types and incomplete symbols in general. The way is not so clear if we read only "On Denoting", where we only find the results of all the former investigations. Now, once the distinction between meaning and denotation is rejected (in the last analysis, the one between Sinn and Bedeutung) by means of the transformation of the first one into something subjective (returning to the Principles), and the second one into something unique, the objective of making clear the mystery of descriptive functions (or denoting and unambiguous complex-concepts) could be realized.

However, these consequences were published, and even then in a very incomplete way, only five years later in Principia (for 1908 was limited to technical progress). Two other effects were the disappear-

${ }^{6}$ I have provided the background for stating the heritage from Frege and Peano regarding the theory of descriptions in my 1992. One of my main points there is to show that Peano already had enough resourses for completely (and symbolically) eliminating the definite article in certain contexts where the required conditions of existence and uniqueness were missing. For a general account of the achievements of the Peano school and its influence on Russell see my I99I, Chaps. 3 and 4.

7 In migos, $\$ 64$, fol. 58, Russell claims for the arbitrariness of conventional denotations, which are eliminated in the system as a consequence of his theory of descriptions. 
ance of the problem of subsistence and the reformulation of the problem of truth. The first one took place only in a secondary way, and not as if Meinong was the "main enemy", as suggested by "On Denoting". The second one, originated by the need to maintain the question within the limits of correspondence with facts (although admitting no "negative facts"), had to require a new theory of judgment, now regarding it as a "multiple-relation" 8 instead of a single one between mind and one entity. ${ }^{9}$

\section{REFERENCES}

Ayer, A. J., 197r. Russell and Moore: the Analytical Heritage (London: Macmillan).

Blackburn, S. and Code, A., 1978. "The Power of Russell's Criticism of Frege", Analysis, 38: 65-77.

Butler, R. J., 1954. "The Scaffolding of the Theory of Descriptions", Philosophical Review, 64: 350-66.

Cassin, C.E., I97o. "Russell's Discussion of Meaning and Denotation: a Re-Examination". In Klemke 1970, pp. 256-72. Coffa, J. A., 1980. "Russell as a Platonic Dialogue: the Matter of Denoting",
Synthese, 45: 43-70.

Grattan-Guinness, I., 1977. Dear Russell-Dear Jourdain (London: Duckworth). Hochberg, H., 1976. "Russell's Attack on Frege's Theory of Meaning", Philo-
sophica, I8: 9-34.

Atomism Thought, Fact and Reference: the Origins and Ontology of Logical Atomism (Minneapolis: U. of Minnesota P.).

Klemke, E. D., ed., 1970. Essays on Bertrand Russell (Urbana: U. of

${ }^{8}$ In my rggo I have shown how some of these consequences were developed with regard to the theory of descriptions itself, whereas in my 1989 I have pointed out the rest of them as to the substitutional theory, the theory of logical types, the generaliz ation of the incomplete symbols and the attempts at developing the new theory of
judgment.

${ }^{9}$ My thanks are due to Nick Griffin for his remarks on a previous version of this paper, which made possible to improve both my English and the content itself. I am also grateful to Ivor Grattan-Guinness for his comments, which allowed some I am improvements, and to the Russell Archivist and editor of his journed some more with the final version and information provided.
Illinois P.).

Rodríguez-Consuegra, F. A., r989. "Russell's Theory of Types, I90I-I9Io: Its Complex Origins in the Unpublished Manuscripts", History and Philosophy of Logic, 10: 13I-64.

-, rg9o. "The Origins of Russell's Theory of Descriptions according to the Unpublished Manuscripts". Russell, 9: 99-I32.

- rogI. The Mathematical Philosophy of Bertrand Russell: Origins and Development (Basel, Boston and Berlin: Birkhäuser).

- r r992. "A Comparison of the Theories of Descriptions by Frege, Peano and Russell". In preparation.

Russell, Bertrand, mrgos. "On Fundamentals", unpublished ms. (8I leaves, RA 230.030710).

_ I I905a. "On Denoting", Mind, I4: 479-493. Reprinted in LK, pp. 4I56.

, I908. "Mathematical Logic as Based on the Theory of Types". American Journal of Mathematics, 30: 222-262. Reprinted in LK, pp. 59-102.

- , rgII. "Knowledge by Acquaintance and Knowledge by Description", Proceedings of the Aristotelian Society, II (1910-II): 108-28. Reprinted in Mysticism and Logic (London: Longmans, Green, 1918).

Searle, J. R., 1958. "Russell's objections to Frege's Theory of Sense and Reference", Analysis, 18: 137-42.

Welding, S. O., 1977. "Frege's Sense and Reference Related to Russell's Theory of Definite Descriptions", Revue internationale de philosophie, 25: $389-402$. 